\title{
Calanthe xhsinchuensis (Orchidaceae), a new natural hybrid from Taiwan
}

Yung-I Lee

\begin{abstract}
Background: Natural hybridization in plants is a vital mechanism of speciation. Calanthe arisanensis and C. sieboldii occur in the same habitat in northern Taiwan, where there are a number of plants whose morphologically characters are similar in between of these two species. In this report, a new natural hybrid, Calanthe species - C. xhsinchuensis Y.I. Lee putatively derived from the natural hybridization of $C$. arisanensis and C. sieboldii was described and illustrated. Besides, somatic chromosome number was counted.

Results: The morphological and histological data of flowers, capsules, roots and leaves of $C$. xhsinchuensis show an intermediate condition between its putative parents. The chromosome number, $2 n=40$, is also congruent with its putative parents. Color plates and line drawings are provided to aid in identification.
\end{abstract}

Conclusion: Base on the morphological characteristics of reproductive and vegetative organs, and the distributions of putative parents, it is proposed that C. xhsinchuensis is a natural hybrid between C. arisanensis Hayata and C. sieboldii Decaisne ex Regel.

Keywords: Calanthe arisanensis; Calanthe sieboldii; Calanthe xhsinchuensis; Calanthe; Taiwan; Chromosome number; Natural hybrid; Orchidaceae

\section{Background}

Natural hybridization is an important mechanism of plant evolution (Arnold, 1997). Fertile hybrids may intercross or backcross with parental species, producing abundant genetic and phenotypic variation for natural selection. The genus Calanthe comprises more than 170 species widely distributed from Africa, Asia, Pacific Islands and Australia (Jin and Li, 2007). This genus is characterized by pubescent roots, often clustered leaves, petals and sepals similar, spurred lip and eight pollinia. In Taiwan, there are 19 species of Calanthe ( $\mathrm{Su}, 2000$; Flora of Taiwan). Calanthe arisanensis is an endemic species with pinkish white flowers that could be found throughout the island at the altitudes about 1000 meter (Lin, 1988; Su, 2000). Calanthe sieboldii is closely related to Calanthe arisanensis with bright yellow flowers that could be found in the northern areas of Taiwan (Lin, 1988; Su, 2000). C. sieboldii is

Correspondence: leeyungi@mail.nmns.edu.tw

Biology Department, National Museum of Natural Science, No 1, Kuan-Chien Rd., Taichung, Taiwan

\section{Springer}

(C) 2013 Lee; licensee Springer. This is an Open Access article distributed under the terms of the Creative Commons Attribution License (http://creativecommons.org/licenses/by/2.0), which permits unrestricted use, distribution, and reproduction in any medium, provided the original work is properly cited. also distributed in Ryukyu Islands, southern Japan and Korea. In northern Taiwan, C. arisanensis and C. sieboldii occur in the same habitat, and they both bloom during March and April. In some natural habitats, besides these two Calanthe species, there are a number of plants whose morphologically characters are similar in between of $C$. arisanensis and C. sieboldii that are considered to be their natural hybrid. In this report, a new Calanthe species putatively derived from the natural hybridization of $C$. arisanensis and C. sieboldii was documented.

\section{Methods \\ Material}

Specimens of Calanthe xhsinchuensis, $C$. arisanensis and C. sieboldii were collected from Jiashih Township of Hsinchu County, Taiwan and cultivated in the greenhouse at National Museum of Natural Science, Taiwan for further morphological comparison, SEM, histological and cytological studies. The vouchers are deposited at TNM. 


\section{Chromosome preparation}

The actively growing root tips were cut and pretreated in $2 \mathrm{mM}$ 8-hydroxyquinoline at $25^{\circ} \mathrm{C}$ for $5 \mathrm{~h}$ to accumulate prometaphase cells, rinsed with distilled water, then fixed in fresh prepared Farmer's fluid (three parts of ethanol to one part of glacial acetic acid). Root tips were macerated with $6 \%$ cellulose (Onoauka R-10, Yakukt Honsha, Japan) and 6\% pectinase (Sigma Chemical Co., St. Louis, Mo.) in $75 \mathrm{mM} \mathrm{KCl}, \mathrm{pH}=4.0$ at $37^{\circ} \mathrm{C}$ for 30 min. After a brief wash with $45 \%$ acetic acid solution, root tips were squashed as described by Aoyama
(1989), then the chromosomes were stained with DAPI in an antifade solution (Vector Laboratories, CA, USA). The images were captured digitally by a CCD camera attached to a Zeiss Axioskop 2 microscope (Carl Zeiss AG, Germany).

\section{Scanning electron microscopy}

The dry seeds were mounted on aluminum stubs with adhesive or silver paint, coated with $30 \mathrm{~nm}$ gold in a sputter coater and observed using a scanning electron microscope (S-3000 N; Hitachi, Japan).

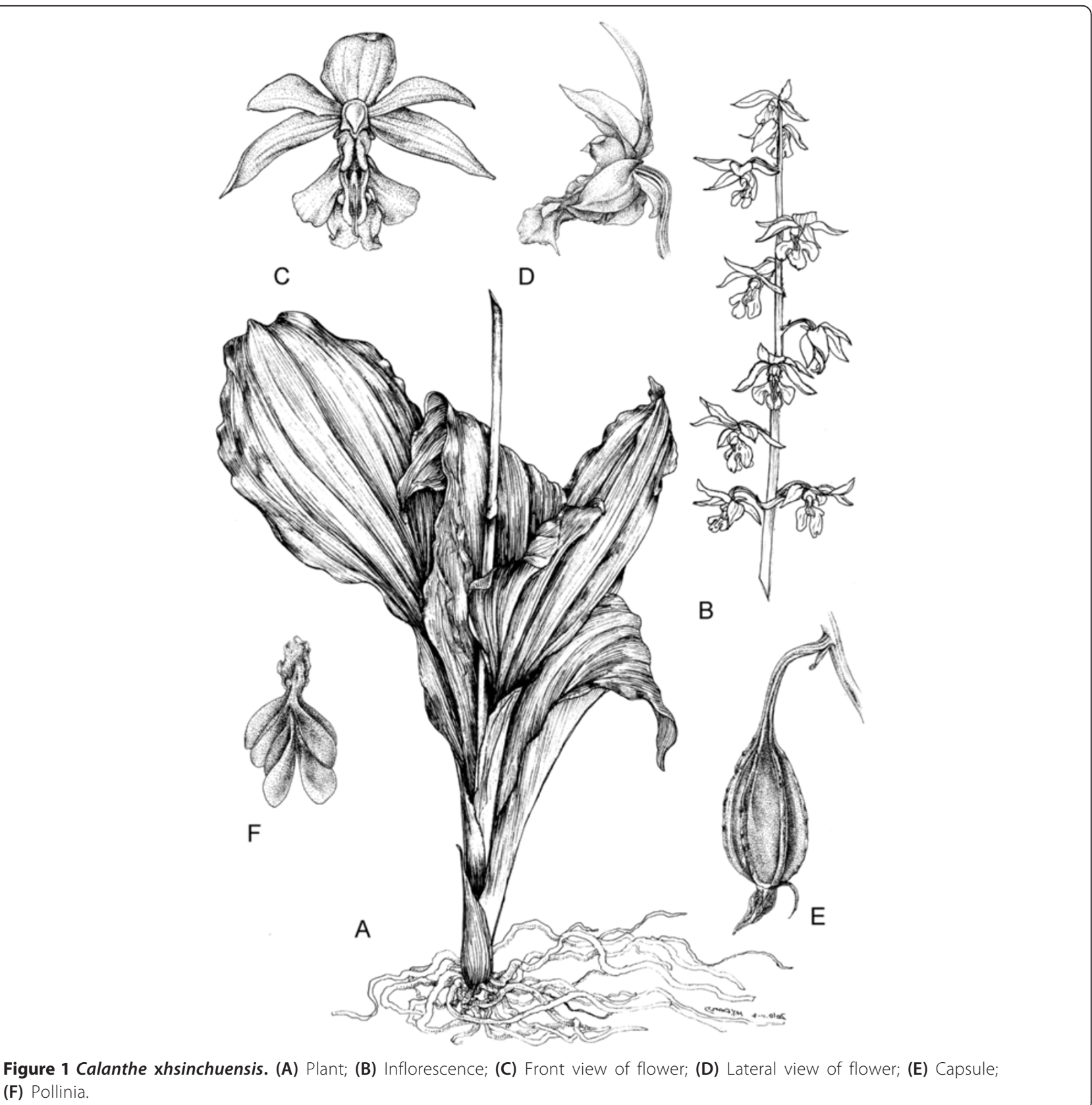




\section{Histological observations}

Root sections were cut and fixed in $2.5 \%$ glutaraldehyde and $1.6 \%$ paraformaldehyde buffered with $0.05 \mathrm{M}$ phosphate buffer, $\mathrm{pH} 6.8$, for 24 hours at $4^{\circ} \mathrm{C}$. After fixation, the samples were rinsed in three 15-min changes of buffer. The materials were dehydrated in an acetone series and embedded in the Spurr's resin (Electron Microscope Sciences, Washington, PA). Sections of $1 \mu \mathrm{m}$ were obtained by a glass knife on an ultramicrotome (Leica, Wetzlar, Germany), and were stained with $0.1 \%$ alkaline TBO for $1 \mathrm{~min}$ at $60^{\circ} \mathrm{C}$ on a hot plate. The sections were viewed and the images were captured digitally using a CCD camera attached to a light microscope (Carl Zeiss AG).

\section{Results and discussion}

Taxonomic treatment

\section{Calanthe xhsinchuensis}

Y.I. Lee, hybr. nov.-TYPE: TAIWAN, Hsinchu County, Jiashih Township, Niao Zui Shan, elev. ca. 1,500 m, 25
Mar 2008, Yung-I Lee 200902 (holotype: TNM). 新竹根 節蘭. Figures 1 and 2.

\section{Diagnosis}

Hybrida natunali e C. arisanensi et C. sieboldii genita, forma foliorum, diam. radicum, labellis, calcaribus et fructibus omnino inter $\mathrm{C}$. arisanensem et $\mathrm{C}$. sieboldii, $\mathrm{ab}$ ambabus plantis $40-60 \mathrm{~cm}$ altis, floribus $4-5 \mathrm{~cm}$ diam, cremeo-flavidis differt.

\section{Terrestrial}

Plants 40 - $60 \mathrm{~cm}$ tall. Pseudobulb globose-ovoid, $3 \mathrm{~cm}$ long, $2 \mathrm{~cm}$ in diam, with 3 or 4 nodes. Leaves $3-4$, elliptic to narrow elliptic, apex acuminate, leaf blade $35-40 \mathrm{~cm}$ long, $6.5-9 \mathrm{~cm}$ wide, not fully opened at anthesis, petiole $5-10 \mathrm{~cm}$ long (Figure 3 ). Inflorescence raceme with 7 to 10 flowers arising with developing leaves and pseudobulbs, about $50-70 \mathrm{~cm}$ long, $4.2-4.9 \mathrm{~cm}$ wide; pedicel with ovary light green, about $2 \mathrm{~cm}$ long, ovary shortly pubescent; floral bracts
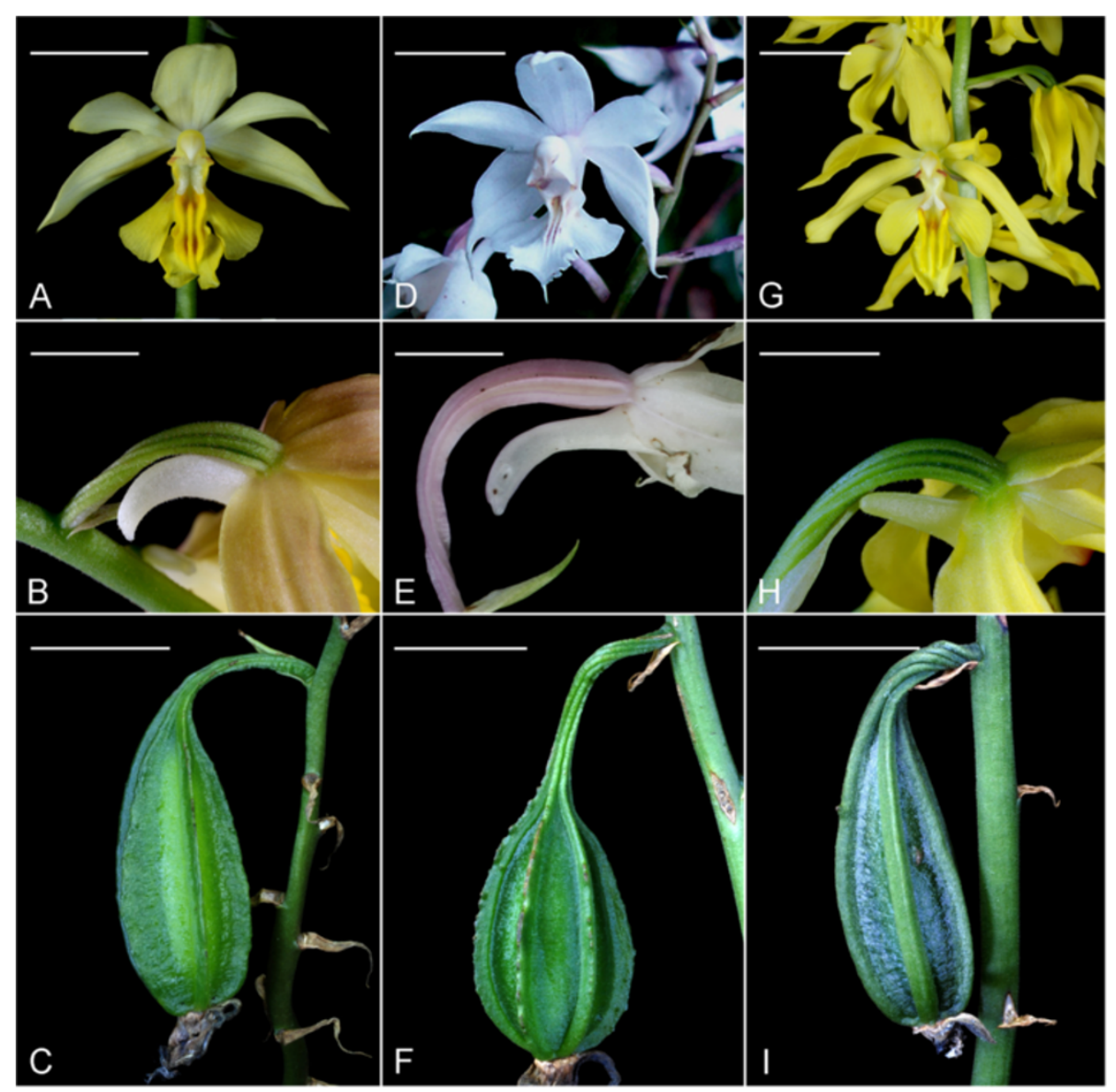

Figure 2 Comparison of Calanthe xhsinchuensis (A-C) with putative parents, C. arisanensis (D-F) and C. sieboldii (G-I). (A, D and G) Flowers, Scale bar $=2 \mathrm{~cm}$; (B, E and $\mathbf{H})$ Spur and ovary, Scale bar $=8 \mathrm{~mm}$; (C, F and I) Capsule, Scale bar $=5 \mathrm{~cm}$. 


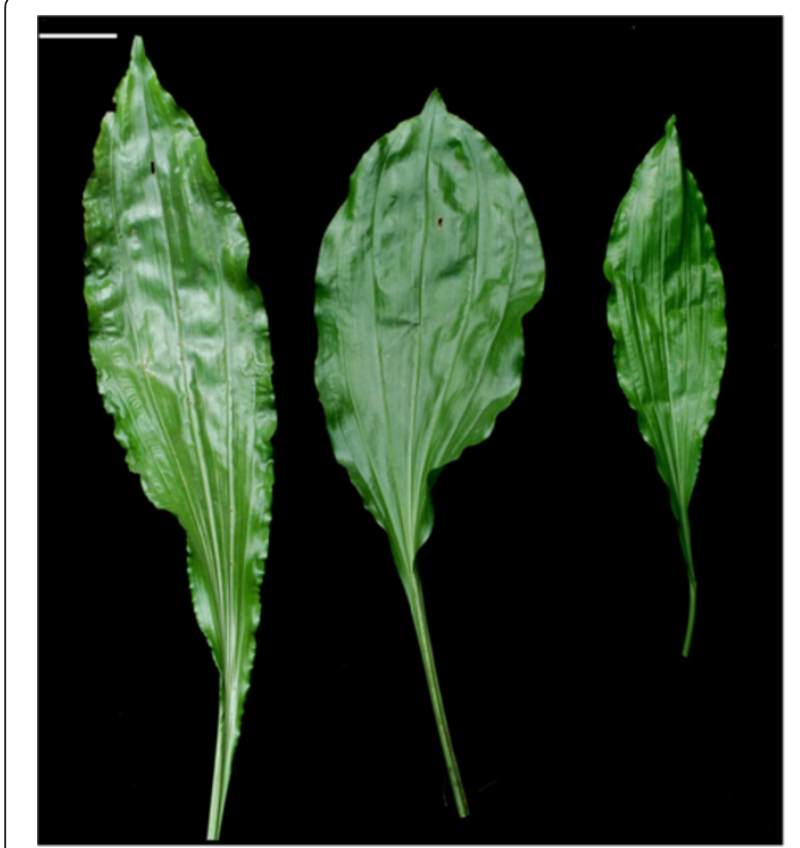

Figure 3 Comparison of leaves of Calanthe xhsinchuensis (left) with putative parents, C. sieboldii (middle) and C. arisanensis (right). Scale bar $=3 \mathrm{~cm}$.

lanceolate, $1-1.5 \mathrm{~cm}$ long. Flowers $4-5 \mathrm{~cm}$ across, creamy yellow; lip with brighter yellowish lobes. Dorsal sepal lanceolate-ovate, $2.5-3 \mathrm{~cm}$ long, $1.2 \mathrm{~cm}$ wide, acuminate at apex, slightly contracted at base; lateral sepals similar, slightly oblique, $2.7-3.2 \mathrm{~cm}$ long, $1.2 \mathrm{~cm}$ wide. Petals oblanceolate, $2-2.4 \mathrm{~cm}$ long, $0.5 \mathrm{~cm}$ wide, acuminate at apex. Lip deeply 3lobed, $2 \mathrm{~cm}$ across, adnate to column at base, spurred; lateral lobes, broadly flabellate or ovate; central lobe oblong, margins undulate, apex emarginate with short aristate; disc with 2 short ridges and 3 slender, long ridges, the basal disc adjacent to column with 2 rows of dense white hairs. Spur white, curved, shortly pubescent $8-12 \mathrm{~mm}$ long. Column stout, $7 \mathrm{~mm}$ long.

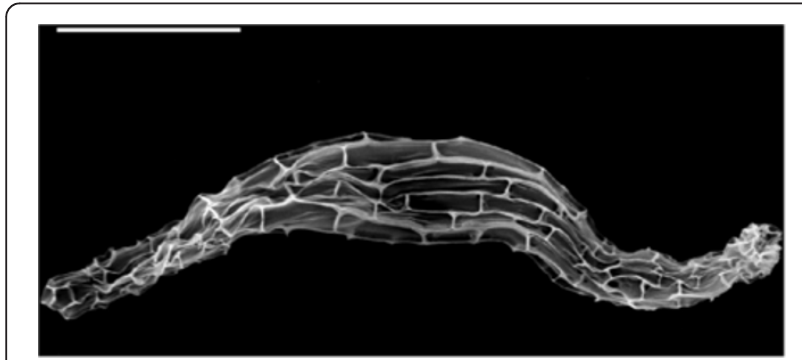

Figure 4 The SEM microphotograph of $C$. xhsinchuensis seed. Scale bar $=200 \mu \mathrm{m}$.
Anther $5 \mathrm{~mm}$ long, cordate; pollinia clavate, orange, $2 \mathrm{~mm}$ long, with short caudicles attached to viscidium; stigma solitary; rostellum bifid, acute at apex. Capsule with 6 lightly longitudinal ridges, $4.8-5.2 \mathrm{~cm}$ long, $1.6-2 \mathrm{~cm}$ wide. The seeds numerous, fusiform with white and transparent seed coat. The seed size about $750 \mu \mathrm{m}$ long, $100 \mu \mathrm{m}$ across (Figure 4). The somatic chromosome number of C. xhsinchuensis is $2 n=40$ that is the same as its putative parents (Tanaka et al., 1981) (Figure 5).

\section{Distribution}

It is known mainly from the mountain area in Jiashih Township (1500 m) of Hsinchu County in northern Taiwan.

\section{Etymology}

The name of this species is derived from the Hsinchu County, the place of its discovery in northern Taiwan.

\section{Notes}

C. xhsinchuensis only occurs at the sites where both C. arisanensis and C. sieboldii could be found together. Base on the comparison of morphological characteristics of reproductive and vegetative organs of C. xhsinchuensis and its putative parental species (Table 1, Figures 2, 3 and 6), it is proposed that this unusual plants occur in Jiashih Township of Hsinchu County is a natural hybrid between C. arisanensis and C. sieboldii.

The root diameter of $C$. xhsinchuensis shows an intermediate condition between its putative parents (Table 1;

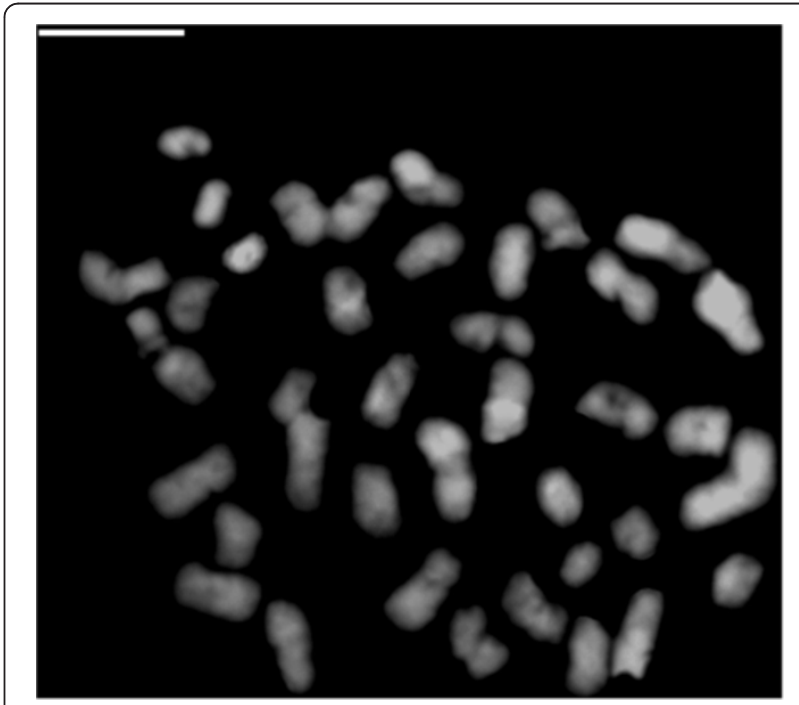

Figure $\mathbf{5}$ Mitotic chromosome of Calanthe xhsinchuensis $(\mathbf{2 n}=\mathbf{4 0})$. Scale bar $=10 \mu \mathrm{m}$. 
Table 1 Comparison of Calanthe xhsinchuensis with putative parents, C. arisanensis and C. sieboldii

\begin{tabular}{llll}
\hline & C. xhsinchuensis & C. arisanensis & C. sieboldii \\
\hline Root diameter $(\mathrm{mm})$ & $1.9-2.1$ & $2.1-2.5$ & $1.5-1.6$ \\
Leaf & & & \\
Leaf shape & Elliptic to narrow elliptic & Narrowly elliptic & Broadly elliptic \\
Length $(\mathrm{cm})$ & $40-55$ & $15-25$ & $35-40$ \\
Width $(\mathrm{cm})$ & $6.5-9$ & $4-4.5$ & $9-12$ \\
Inflorescence & & & $50-80$ \\
Length (cm) & $50-70$ & $25-40$ & $4.9-5.1$ \\
Width (mm) & $4.2-4.9$ & $3.1-3.2$ & \\
Flower & & & Yellow \\
Tepal color & Creamy yellow & Pinkish white & $4-5$ \\
Spur (mm) & $8-12$ & $14-15$ & Antrorse \\
Spur shape & Curved & Curved & \\
Capsule & & & Capsule without conspicuous longitudinal \\
Capsule shape & Capsule with 6 lightly longitudinal & Capsule with 6 longitudinal & wing-like ridges \\
Length (cm) & wing-like ridges & wing-like ridges & $5.1-5.3$ \\
Width (cm) & $4.8-5.2$ & $5.2-6.1$ & $1.5-1.7$ \\
\hline
\end{tabular}

Figure 6). The root diameter of C. arisanensis (Figure 6B) is the thickest among the three species, whereas the root diameter of $C$. sieboldii (Figure $6 \mathrm{C}$ ) is the thinnest. The velamen of $C$. xhsinchuensis is 4 to 5 celled-wide, and the cortex is 8 to 9 celled-wide (Figure 6A). The hyphae, and pelotons could be found in the cells of the cortex. The other features, including leaf shape (Figure 3) and flower color (Figures 2A,D and G) of $C$. xhsinchuensis are intermediate between those of $C$. arisanensis and C. sieboldii. The spur shape of $C$. xhsinchuensis is curved that is similar to the spur shape of $C$. arisanensis; while the ovary color of $C$. xhsinchuensis is light green that is similar to the ovary color of C. sieboldii (Figures 2B,E and $\mathrm{H}$ ). The capsule shape of $C$. arisanensis is characterized by having 6 longitudinal wing-like ridges, while $C$. sieboldii has no conspicuous wing-like ridges on its capsule. C. xhsinchuensis has 6 lightly longitudinal ridges on the capsule, showing an intermediate condition (Figures 2C,F and I).

\section{Conclusion}

All the available data and the distributions of putative parents support the recognition of the new species C. xhsinchuensis is a natural hybrid between C. arisanensis Hayata and C. sieboldii Decaisne ex Regel.

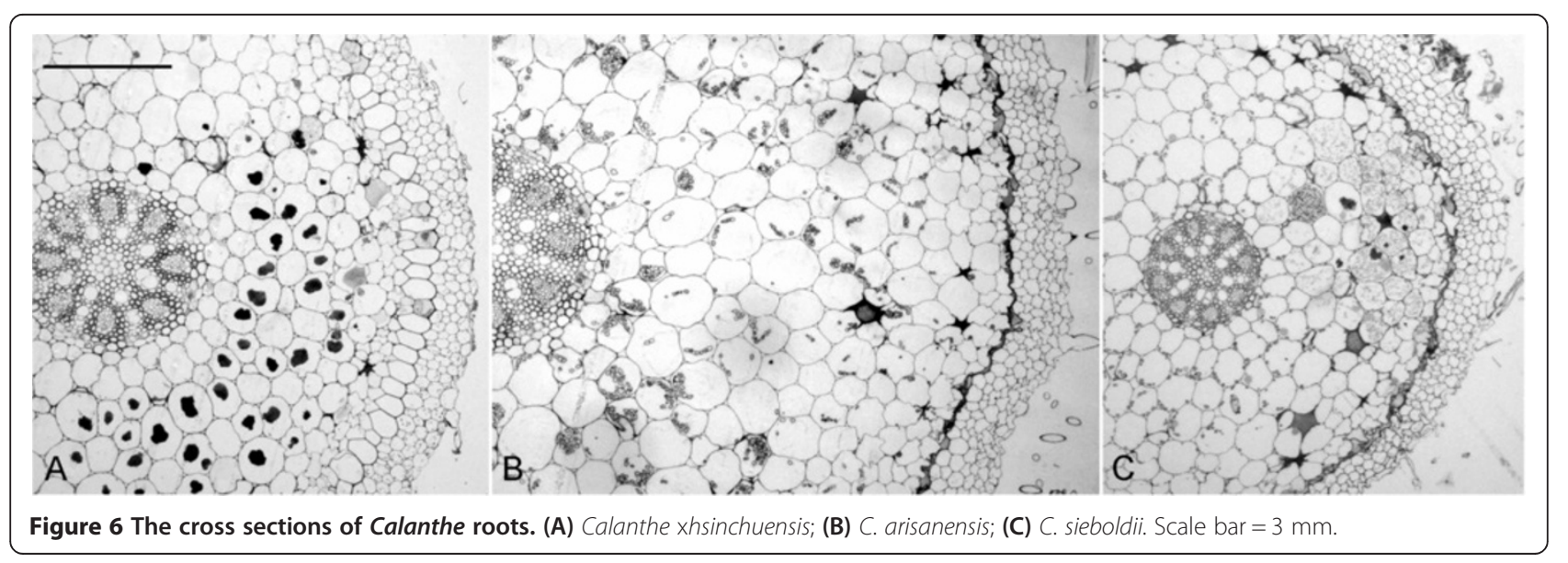




\section{Competing interests}

The author declares that all competing interests are listed before the references.

\section{Acknowledgments}

I appreciate the financial support from National Museum of Natural Science; Mr. Ding Fang for the Latin diagnosis; Mr. Wei-Min Lin for field work assistance.

Received: 31 August 2011 Accepted: 12 November 2012 Published: 30 August 2013

\section{References}

Aoyama M (1989) Karyomorphological studies in Cymbidium and its allied genera. Orchidaceae Hiroshima Bot Gard Bull 11:1-121

Arnold ML (1997) Natural Hybridization and Evolution. Oxford University Press, New York

Jin XH, Li H (2007) A new species of Calanthe (Orchidaceae) from Yunnan. China Nord J Bot 25:20-22

Lin TP (1988) Native Orchid Species of Taiwan vol. 2. Southern Materials Center, Inc, Taipei, Republic of China

Su HJ (2000) Orchidaceae. In: Huang TC (ed) Flora of Taiwan, vol 5, 2nd edn. Editorial Committee of the Flora of Taiwan, Department of Botany, National Taiwan University, Taipei, Taiwan, pp 729-1086

Tanaka R, Karasawa K, Ishida G (1981) Karyomorphological observation on Calanthe. Japan Bull Hiroshima Bot Gard 4:9-62

doi:10.1186/1999-3110-54-25

Cite this article as: Lee: Calanthe xhsinchuensis (Orchidaceae), a new natural hybrid from Taiwan. Botanical Studies 2013 54:25.

\section{Submit your manuscript to a SpringerOpen ${ }^{\circ}$ journal and benefit from:}

- Convenient online submission

$\checkmark$ Rigorous peer review

- Immediate publication on acceptance

- Open access: articles freely available online

- High visibility within the field

- Retaining the copyright to your article 